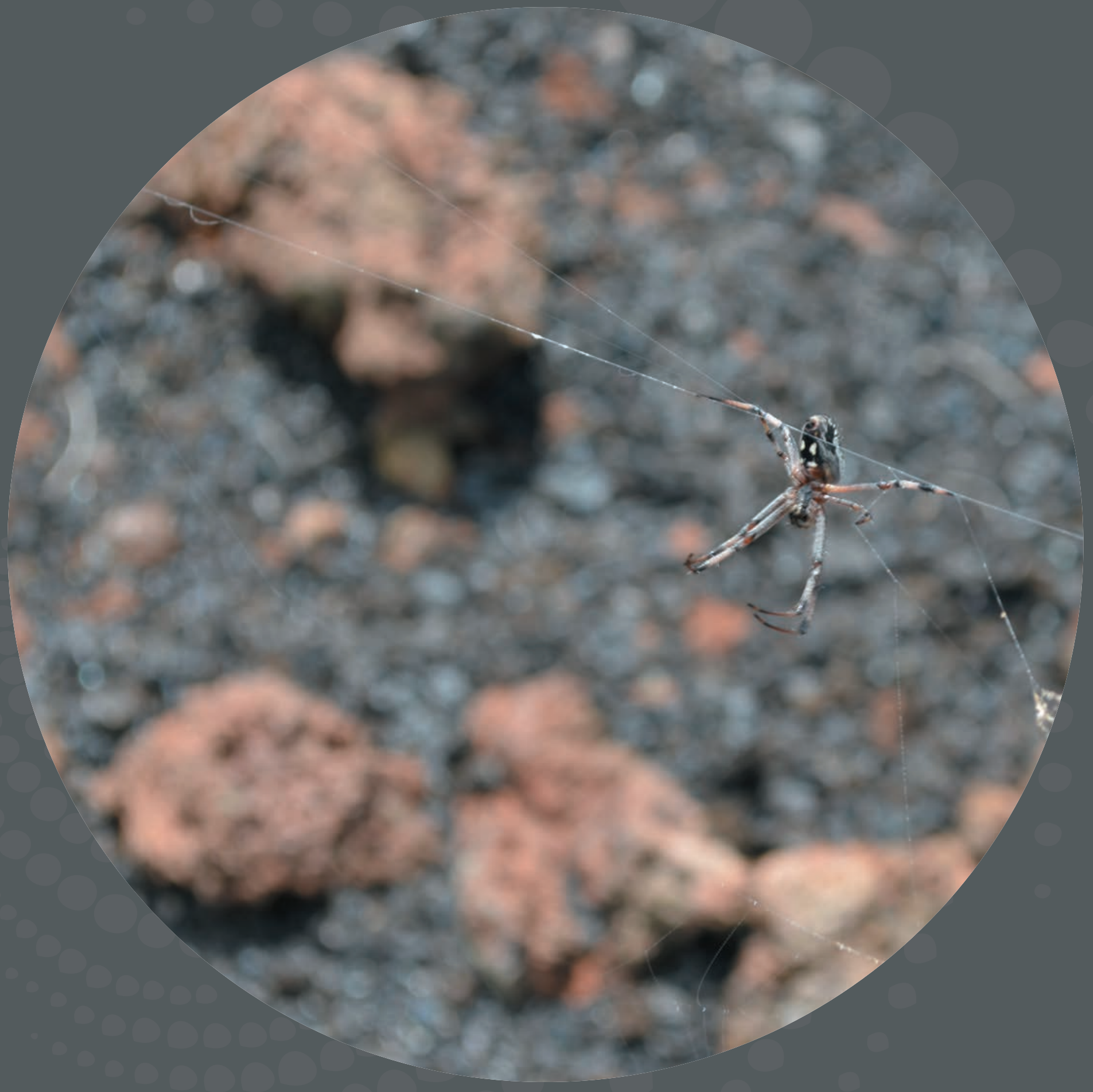

DÍA A DÍA EDUCATIVO: CRÓNICAS 



\section{LAS PLAZAS DE MERCADO: PERSISTENCIA DE LA PROVINCIA}

\author{
Santos Balberdy Peña Blandón \\ Laboratorista Dental \\ Docente vinculado al Programa de Seguimiento a Egresados \\ Universidad Santo Tomás \\ Sabepla7yahoo.es
}

\author{
Yeimy Susana Salazar \\ Laboratorista Dental \\ Docente Universidad Santo Tomás \\ Yeimysalazar_worldente@hotmail.com
}

Mañana de domingo y todos los domingos vienen acompañados de un aire único, son como el hermano alcahuete, que te permite hacer lo que quieres, inclusive levantarte tarde, no importa que este soleado o encapotado, son simple y llanamente especiales e incomparables con el resto de sus hermanos. Las personas caminan desprevenidamente, sin afanes parece que nadie lleva rumbo fijo. Es la típica actitud dominguera. Sin embargo, nosotros teníamos nuestra meta: la plaza de mercado.

Ahhhhh, las plazas de mercado ¿será que las grandes cadenas de supermercados las van a desplazar? Sería una gran pérdida, pues cada salida del sol da inicio a un nuevo día en una plaza de mercado en el mundo. Allí las labores empiezan muy temprano y se prolongan hasta que el sol se oculta. Hombres y mujeres de todas las edades disponen en forma no necesariamente ordenada, productos que, en su mayoría, son traídos del campo o de manos de artesanos.

Las plazas de mercado son los centros económicos y sociales de los pueblos, allí se realizan todas las transacciones comerciales: comprar, vender y cambiar. Es aquí donde los comunes y corrientes mortales nos proveemos de nuestros alimentos, y es aquí en donde la vida cotidiana transcurre de forma espontánea, en donde se cruzan realidades y sabidurías. En donde consigues desde el enhebrador de hilo, para aquellos que ya la visión no les da para más, hasta el puesto de yerbas con su palo santo, para espantar zancudos y aromatizar el ambiente. También encontramos las grandes promociones:

- Doña Marleny cuánto vale ese saldo de naranjas, llévelo por $\$ 5.000$.

- Ahh pero no me alcanza, sólo tengo cuatro mil y me tiene que quedar para la papa.

- Está bien habrá la bolsa y lléveselo, a ver si me voy temprano.

- Gracias doña Marleny, ¿y será que me encima esa ramita de cilantro?

Esas son las plazas de mercado, las de antes, las de ahora, las de siempre. Donde escogemos los mejores vegetales por el poder del tacto y del olfato. Donde se piden rebajas, ñapas, se reciben consejos sobre cómo cocinar los alimentos de mil y una manera. Seleccionamos la carne que hago moler y limpiar a mi gusto. Incluso sé en qué temporada se dan algunas frutas, cuál es el mejor sitio para comprar aguacates, dónde venden las mejores mazorcas, dónde es más rico el pollo.

\section{Los personajes}

Más allá de lograr los alimentos más frescos y considerados nutritivos porque son escogidos libremente está la interacción con los vecinos y vendedores que en ocasiones son más que eso. Por ejemplo, Doña Marleny, la señora del puesto de víveres y frutas, pregunta siempre por mi familia a tiempo que me recomienda las mejores piñas y los mejores melones cuando 
voy a su puesto. Doña Marta, la de los huevos criollos (qué desabridos me parecen los huevos industriales ahora), me cuenta con gran orgullo de sus hijos, próximos ya a ser bachilleres.

Don Efraín, es el esposo de doña Marleny, un hombre con unas manos grandes, que parecían una pala de esas con que mezclan el cemento para las construcciones, alto, corpulento, de espaldas grandes, serias pero amables y serviciales. Trabajaba con su esposa y sus dos hijos adolescentes, y todos antes de verme llegar al puesto, ya te están saludando.

- ¿Que necesita señor, señora o señorita? tengo arroz y azúcar venezolanos a $\$ 1.800$ el kilo, no me queda si no lo que ve.

- Y usted lo trae o se lo traen hasta aquí, preguntamos desprevenidamente,

- Yo lo cargo en el Km 18 vía Cúcuta, allá tengo mi parcela y cargo mi camión con las legumbres, las frutas y mi familia para estar aquí sábado y domingo, y en la noche vuelvo a la tarea diaria; pero cada vez se pone más escaso por los problemas en Venezuela, no demora en subir el precio.

-¡Qué se va hacer! igual toca pagarlo porque a esto de la comida no se le puede hacer la cur$v a$,-comentó un parroquiano que escuchaba la conversación.

- Bueno don Efra, muchas gracias, nos vemos la otra semana, hasta luego doña Marleny, chao muchachos, cuídense.

\section{A la semana siguiente}

A la semana siguiente, nos dirigimos a la plaza nuevamente, solo que ya no fue el domingo sino el sábado.

Plaza de mercado que se respete, tiene su propio loco (a) reconocida y esta no era la excepción, la divisamos a lo lejos, pidiendo algo en un puesto de frutas. Logró su cometido y se retiró comiéndose un mango, y llevando debajo del brazo un pedazo de yuca y una zanahoria

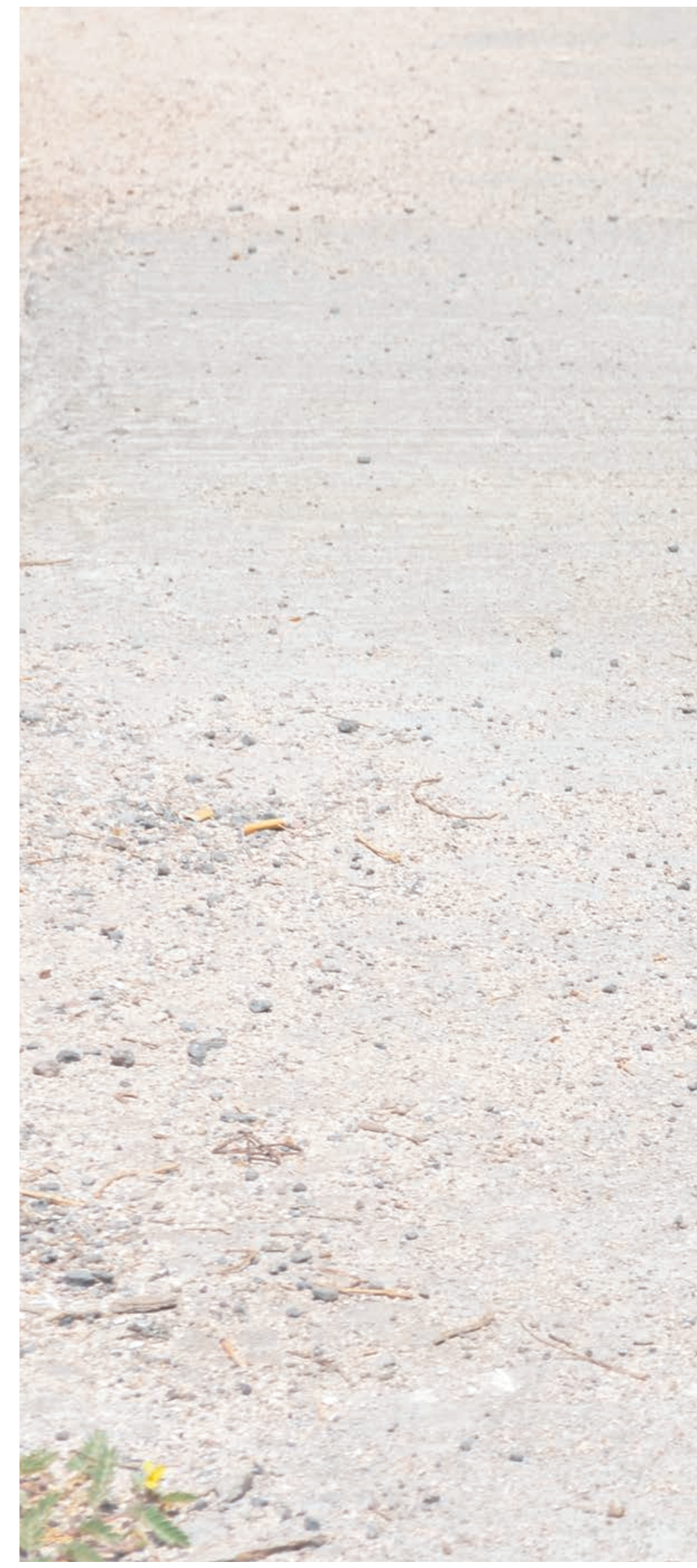




$$
1
$$


que encontró en el piso. Continuamos caminando y preguntando precios, la cebolla está cara por lo del paro, dijo Amparo, la vendedora y continuamos nuestro sondeo de la canasta familiar.

Llegamos al puesto de don Efraín, uno de los hijos, extendía algunas frutas en unos mesones de madera que hacían parte del amoblado de la plaza de mercado, fijos al piso con tornillos para que no se movieran, pero otros estaban desocupados, miramos alrededor y tampoco estaba doña Marleny, solo estaba uno de sus hijos, el mayor, con unos pocos kilos de arroz y azúcar venezolana, le preguntamos,

¿¡Y las naranjas, no trajeron hoy?

-No señor- respondió.

¿YY legumbres tampoco?

-No señor, volvió a responder
- ¿Y su papá y su mamá?

- Tampoco señor, mi mamá no pudo venir, porque mi papá tuvo un accidente el miércoles en el camión y falleció bajando del páramo de Berlín.

Quedamos en silencio unos segundos, por nuestras cabezas pasó la escena de ocho días atrás en esta plaza cuando hacíamos nuestro mercado. No tenemos el talento para preguntar cómo suceden las cosas tristes, simplemente le dijimos que lo lamentábamos, que nos saludara a doña Marleny y a su hermano, y que me hiciera el favor de venderme dos kilos de azúcar y dos kilos de arroz.

Nos despedimos con un apretón de manos, y coincidimos en que nos pareció apretar la mano de don Efraín. Le dijimos: tienes las mismas manos fuertes de tu papá, nos vemos. Se miró sus manos y sonrió. 